www.nature.com/aja

\title{
EDITORIAL
}

\section{Surgeries in andrology: optimization and patients' well being}

Asian Journal of Andrology (2013) 15, 3-4; doi:10.1038/aja.2012.147; published online 17 December 2012

$\mathrm{T}$ he world is driven by technology, and information is increasing at an unprecedented rate. Harnessing this enormous drive, Andrology has become an established part of modern medicine, and andrological surgery is evolving continuously, including the advent of robotic technology. We all recognise the necessity for the proper evaluation of new developments in this exciting field. In this context, we are pleased to present this 2013 Asian Journal of Andrology special issue focusing on "Surgeries in Andrology". This special issue is intended to provide a concise and substantive update for surgical treatments of conditions related to male sexual dysfunction and male fertility.

\section{Male sexual dysfunction}

Although the introduction of phosphodiesterase type 5 (PDE5) inhibitors in 1998 revolutionized the treatment of erectile dysfunction (ED), about $1 / 3$ of men with ED are not helped by the therapy and require second- or third-line therapies. For young men with localized penile arterial insufficiency secondary to perineal or pelvic trauma, penile revascularization surgery is a viable option. The essence of the surgery is to connect the inferior epigastric artery to the dorsal artery of the penis bypassing the occluded proximal cavernous artery. The increased perfusion pressure then directs flow through the collateral arteries to the cavernous artery to provide more blood flow during erection. Dicks and associates ${ }^{1}$ who are the experts in revascularization surgery described the pathophysiology, indication, and surgical results of their microvascular surgery technique. A number of men suffered from ED and stress urinary incontinence after radical prostatectomy and radical cystectomy. Lee et $a l^{2}$ reviewed the literature and reported their experience of implanting both penile prosthesis and artificial sphincter or male sling simultaneously. It is convincing that implantation of both devices together produced excellent results in centers that are experienced in device implantation without an increase in complication rate. Urologists are often faced with difficult task of reconstructing the glans, penile shaft and scrotum secondary to trauma, excision of benign and malignant diseases or in cases of gender reassignment surgery and aphallia. Garaffa and associates, ${ }^{3}$ one of the most experienced groups in the world, discussed the recent advances, and shared their surgical technique, cosmetic and functional outcome. For ischemic priapism that has failed intracavernous injection of diluted alpha adrenergic agonist, various shunting procedures have been described to create a temporary shunting of blood from the corpus cavernosum to the glans, corpus spongiosum or dorsal/ saphenous veins. Because ischemic priapism is uncommon and a placebo-controlled study is lacking, the current guidelines are largely based on expert opinions. Nevertheless, it is clear that most of the ischemic priapism of less than $24 \mathrm{~h}$ duration responded well to aspiration and injection of diluted alpha-adrenergic agonist. The challenge is in those that extend more than 24 or $48 \mathrm{~h}$. In a recent report from China, Zheng et al. ${ }^{4}$ concluded that severe ED caused by prolonged duration is irreversible, and long-term PDE-5 inhibitor treatments are ineffective. Therefore, the article by Kovac et al..$^{5}$ that proposes aggressive shunting and tunneling based on duration of priapism may provide better results in bringing down the unwanted painful erection as well as preserving potency. The contemporary surgical treatment of penile deformity secondary to Peyronie's disease was summarized by Levine and Larsen. ${ }^{6}$ In general, plication surgeries to shorten the longer side have excellent postoperative results in simple curvature. In those with narrowing and complicated deformity, a grafting procedure is needed although grafting surgery is associated with higher incidence of ED, recurrence and altered penile sensation. To decrease these complications in men with large calcified/ossified plaque, instead of total excision, a tunicapreserving procedure was reported by Eisenberg et al. ${ }^{7}$ with satisfactory results.

\section{Male fertility}

Dramatic advances in the diagnosis and treatment of male infertility allow conception for couples previously considered untreatable. The advent of in vitro fertilization combined with intracytoplasmic sperm injection (IVF/ ICSI) has revolutionized the treatment of male factor infertility. Furthermore, treatment by urologists trained in male reproductive medicine and microsurgery can induce sperm production in men and/or extract sperm from men who have zero sperm counts. In addition, treatments can upgrade the fertility of the infertile men from nothing to candidates for IVF/ICSI, from only IVF/ICSI to intrauterine insemination, and often enable naturally conceived pregnancies. The advances in sperm retrieval techniques described in this issue by Dabaja and Schlegel ${ }^{8}$ as well as Bernie et al., ${ }^{9}$ and refinements in the microsurgical management of obstructive azoospermia, described in this issue by Herrel and $\mathrm{Hsiao}^{10}$ for vasovasostomy, and Chan ${ }^{11}$ as well as Zhao et al. ${ }^{12}$ for vaso-epididymostomy, have resulted in substantially improved pregnancy rates.

In addition, varicocele, most commonly associated with infertility, has now been shown to be associated with a more rapid decline in testosterone levels compared with age-matched men without varicocele. Thus treatment of varicocele, a risk factor for infertility, can also treat and prevent androgen deficiency in the male. Furthermore, treatment of adolescent varicocele has now been shown to restore testicular growth lag and may prevent both future infertility and androgen deficiency, which would be far more cost-effective than treating infertility and androgen deficiency after it occurs. These issues 
are discussed in this issue by Mehta and Goldstein, ${ }^{13}$ and include a detailed description of the microsurgical technique of varicocelectomy.

Microsurgery is such an integral part of male infertility treatment that training is essential for acquisition of the skills necessary to perform these procedures, some of which are amongst the most technically demanding of all microsurgical procedures. In this issue, Mehta and $\mathrm{Li}^{14}$ describe such training. Finally, pushing the envelope, is the beautiful description by Parekattil and Gudeloglu ${ }^{15}$ of robot-assisted microsurgical procedures.

The future of andrological surgery is exciting and, in this issue, we present the cutting edge developments in the field of andrological surgeries about male sexual dysfunction and fertility. We thank the authors and reviewers who concentrated their expertise, time, and effort on this collection. It is our sincere hope that this special issue brings our readers impetus and provides sufficient information to help practitioners appreciate the breakthroughs in the field and guide them in improving and optimizing their practices, and ultimately benefits the patients.

We wish the readers a happy and productive New Year!

\section{Guest Editors for this special issue:}

Prof Tom F Lue, MD, DSc (Hon), FACS

Professor and Vice Chair, Emil Tanagho Endowed Chair in Clinical Urology, Department of Urology University of California, San

Francisco, CA 94143-0738, USA

(E-mail:TLue@urology.ucsf.edu)

Professor Marc Goldstein, MD, DSc (Hon), FACS

Matthew P. Hardy Distinguished Professor of Reproductive Medicine and Urology, Weill-Cornell Medical College of Cornell University,

Surgeon-in-Chief, Male Reproductive Medicine and Surgery, New York Presbyterian Hospital, Weill Cornell Medical Center, New York NY 10065, USA

(E-mail:mgoldst@med.cornell.edu)
1 Dicks B, Bastuba MD. Goldstein I. Penile revascularization-contemporary update. Asian J Androl 2012; e-pub ahead of print December 17 2012. doi: 10.1038/ aja.2012.146.

2 Lee D, Romero C, Alba F, Westney OL, Wang R. Simultaneous penile prosthesis and male sling/artificial urinary sphincter. Asian J Androl 2012; e-pub ahead of print December 3 2012. doi: 10.1038/aja.2012.115.

3 Garaffa G, Sansalone S, Ralph DJ. Penile reconstruction. Asian J Androl 2012; e-pub ahead of print March 19 2012. doi: 10.1038/aja.2012.9.

4 Zheng DC, Yao HJ, Zhang K, Xu MX, Chen Q et al. Unsatisfactory outcomes of prolonged ischemic priapism without early surgical shunts: our clinical experience and a review of the literature. Asian J Androl; 2012; e-pub ahead of print August 27 2012; doi: 10.1038/aja.2012.63.

5 Kovac JR, Mak SK, Garcia MM, Lue TF. A pathophysiology-based approach to the management of early priapism. Asian J Androl 2012; e-pub ahead of print December 3 2012. doi: 10.1038/aja.2012.83.

6 Levine LA, Larsen SM. Surgery for Peyronie's disease. Asian J Androl 2012; e-pub ahead of print November 26 2012. doi: 10.1038/aja.2012.92.

7 Eisenberg ML, Smith JF, Shindel AW, Lue TF. Tunica-sparing ossified Peyronie's plaque excision. BJU Int 2011; 107: 622-5.

8 Dabaja AA, Schlegel PN. Microdissection testicular sperm extraction. An update. Asian J Androl 2012; e-pub ahead of print December 17 2012. doi: 10.1038/ aja.2012.141.

9 Bernie AM, Ramasamy R, Stember DS, Stahl PJ. Microsurgical epididymal sperm aspiration: indications, techniques and outcomes. Asian J Androl 2012; e-pub ahead of print November 19 2012. doi: 10.1038/aja.2012.114.

10 Herrel L, Hsiao W. Microsurgical vasovasostomy. Asian J Androl; 2012; e-pub ahead of print November 12 2012; doi: 10.1038/aja.2012.79.

11 Chan PT. The evolution and refinement of vasoepididymostomy techniques. Asian J Androl 2012; e-pub ahead of print November 19 2012. doi: 10.1038/ aja.2012.80.

12 Zhao L, Deng CH, Sun XZ, Chen Y, Wang WW et al. A modified single-armed technique for microsurgical vasoepididymostomy. Asian J Androl; 2012; e-pub ahead of print 8 October 2012; doi: 10.1038/aja.2012.100.

13 Mehta A, Goldstein M. Microsurgical varicocelectomy: a review. Asian J Androl 2012; e-pub ahead of print November 12 2012. doi: 10.1038/aja.2012.98.

14 Mehta A, Li PS. Male infertility microsurgical training. Asian J Androl 2012; e-pub ahead of print November 19 2012. doi: 10.1038/aja.2012.86.

15 Parekattil SJ, Gudeloglu A. Robotic assisted andrologicall surgery. Asian J Androl 2012; e-pub ahead of print December 17 2012. doi: 10.1038/aja.2012.131. 